\title{
PRAGMATISMO, PLURALISMO Y POSTMODERNISMO (1998)
}

\author{
Richard RORTY \\ Standford University \\ (Traducción de Antonio Gómez Ramos)
}

La palabra "postmodernismo", a fuerza de significar tantas cosas diferentes, ha terminado por quedar prácticamente vacía de significado. Si cogemos al azar una docena de los miles de libros cuyo título contiene la palabra postmoderno, encontraremos, como mínimo, otras tantas definiciones de este adjetivo, todas ellas enormemente divergentes entre si. He insistido muchas veces en que nos las arreglaríamos mucho mejor sin usar esta palabra, que es demasiado borrosa para transmitir nada ${ }^{1}$. Para los propósitos de este ensayo, sin embargo, adoptaré otra táctica. Incluso si la palabra "postmoderno" es demasiado equívoca para que podamos sacar provecho de ella, su popularidad entre los intelectuales podría entenderse si se da alguna explicación. De modo que voy a ofrecer una sugerencia de porqué tanta gente inteligente y reflexiva parece pensar que todo se ha vuelto muy diferente en tiempos recientes.

Por variadas que sean las definiciones de "postmoderno", la mayoría de ellas tienen algo que ver con la percepción de una pérdida de unidad. Mi sospecha es que esta sensación de pérdida es el resultado de que hayan confluido un movimiento filosófico que ya tiene casi un siglo y la conciencia de que las instituciones de la democracia liberal podrían no durar mucho más tiempo. La sensación de que todo ha quedado hecho pedazos resulta de combinar la renuncia a la tradicional creencia teológico-metafísica de que la Realidad y la

1 Para un tratamiento de este tema que comparto cordialmente, puede verse, Bernard YACK, The Fetishism of Modernities, Ithaka, Nueva York, Cornell University Press, 1997, especialmente el capitulo titulado "Postmodernism: the figment of a fetish". 
Verdad son Una -que hay Una Explicación Verdadera de Cómo Son las Cosas Realmente- con la incapacidad para creer que las cosas vayan a mejorar, que la historia culminará algún día en la adopción universal de costumbres e instituciones igualitarias y democráticas. La renuncia comenzó, según mi argumento, con la explicación que dio Darwin acerca de nuestro origen. La incapacidad de creer ha ido progresivamente en aumento durante las últimas décadas, conforme se ha hecho claro que Europa ya no manda en el planeta, y que el futuro sociopolítico de la humanidad se ha vuelto extremadamente imprevisible.

Como es sabido, Freud dijo que Copérnico, Darwin y él mismo habían sido responsables de tres sucesivos cataclismos descentradores: del planeta tierra, de la especie humana, y de la conciencia, respectivamente. Continuando esta metáfora, podemos decir que el siglo XIX estaba dispuesto a abandonar la convicción de que el universo había sido creado y existía para nuestra especie a cambio de la creencia en que la raza humana se había hecho al fin con el control de su destino. Pero esa visión iba ligada a la creencia de que Europa era el centro del mundo, creencia que en las postrimerías del siglo XX ya no se puede sostener. Mientras los intelectuales del siglo XIX emprendieron la sustitución del confort metafísico por la esperanza histórica, los intelectuales del final de este siglo, que se sienten defraudados por la historia, están experimentando una desesperanza autoindulgente y patética.

Mi explicación de estos cambios se dividirá en dos partes: la primera de ellas enfatiza la importancia de Darwin para el desarrollo del utilitarismo, el pragmatismo y la esperanza social del siglo XX; la segunda toma como punto de partida la explicación de nuestra situación histórica presente, tal como la ofrece Clifford Geertz en su reciente libro $A$ World in Pieces ${ }^{2}$.

Platón y la teología cristiana ortodoxa nos contaban que los seres humanos tienen una parte animal y una parte divina. La parte divina es un ingrediente extra añadido. Su presencia dentro de nosotros da testimonio de la existencia de otro mundo superior, inmaterial e invisible: un mundo que nos ofrece la salvación del tiempo y del azar.

Esta explicación dualista es plausible y potente. Somos, ciertamente, muy diferentes de los animales, y la diferencia parece ser de tal género que no se

2 Clifford GeerTZ, $A$ World in Pieces (de próxima aparición). 
puede explicar simplemente por la complejidad. Lucrecio y Hobbes intentaron decirnos que esa complejidad era, de hecho, suficiente - que la mejor forma de entendernos, como a todo lo demás en el universo, es como ensamblajes de partículas producidos artificialmente. Pero antes de Darwin, esta explicación no había alcanzado nunca seguidores de importancia. Para los platónicos y los cristianos, resultaba fácil argüir que las filosofias materialistas no eran más que intentos perversos de devolvernos a la condición animal.

Sin embargo, Darwin hizo del materialismo algo respetable. Su explicación de nuestra diferencia entre nosotros y las bestias se convirtió en algo de sentido común para el público culto. Esto ocurrió por dos razones. La primera era que Darwin había conseguido dar la primera explicación detallada y plausible de cómo surgieron la vida y la inteligencia a partir de un torbellino insignificante de corpúsculos. (Lucrecio y Hobbes no tenían ninguna narración concreta que ofrecer, sólo una posibilidad teórica y abstracta). Pero la narración de Darwin, una vez que se pudo rellenar en sus detalles con la genética mendeliana y con la explosión de la investigación paleontológica, fue lo bastante convincente como para amenazar a toda la tradición teológica y filosófica occidental. Fue el primer drama que retó en serio al mito platónico de la caverna y la Divina Comedia de Dante. Logro imaginativo al mismo nivel de estas grandes obras, esta narración ofrecía la misma combinación de cuento de investigación y síntesis teórica.

Sin embargo, la teoría de Darwin nunca habría llegado a ser de sentido común para los intelectuales europeos si previamente no hubieran abonado el terreno las revoluciones democráticas del siglo XVIII y la Revolución Industrial. Tomadas en conjunto, estas revoluciones testimoniaban el poder de los seres humanos para cambiar las condiciones de la vida humana; permitieron a los europeos del siglo XIX sentir confianza en la capacidad de la humanidad para hacerse cargo de sus propios asuntos. A diferencia de sus antecesores, estos europeos sentían que podían arreglárselas por sí mismos, que podían alcanzar la perfección humana sin tener que apoyarse en un poder no humano.

En épocas anteriores, sólo la presencia de semejante poder parecía explicar el hecho de que no vivimos, o al menos no deberíamos hacerlo, como animales. Los intelectuales daban por hecho que estábamos vinculados a los dioses por un especial favor divino, o por una connaturalidad con lo divino que se ponía de manifiesto en nuestra posesión de un ingrediente extra afiadido, del que los animales carecían: el alma o la razón. Si no existiera tal ingrediente o 
vínculo, argumentaba Platón, la vida de Sócrates no tendría sentido. Pues no habría ninguna razón para no volver a la bestialidad de hombres como Cleonte o Calicles.

Antes y después de Patón, los pensadores religiosos creían que las órdenes y las intervenciones providenciales de una deidad o deidades personales eran necesarias para que los hombres convivieran en paz y concordia. En Platón y en la tradición filosófica secular que él ayudó a fundar, lo divino estaba despersonalizado, privado de voluntad y emoción. Pero teístas y secularistas coincidían en que los humanos podemos hacer algo más que sólo luchar para sobrevivir y alimentarnos, porque compartimos mutuamente algo precioso de lo que los animales carecen. Este extra precioso nos da la capacidad de cooperar. Lo hacemos porque se nos ordena que lo hagamos así, ya sea Dios o algo parecido a la facultad kantiana, pura y no empírica, de la razón práctica.

Pero en la Europa y América del siglo XIX, un gran número de intelectuales empezó a preguntarse si sus predecesores no habrían dependido excesivamente de la idea de la moralidad como obediencia - como conformidad con algo así como los diez mandamientos, o la idea platónica de bien, o el imperativo categórico de Kant. Cuando Blake escribió que "una ley para leones y bueyes es opresión", y Shelley que los poetas eran los legisladores no reconocidos del mundo, estaban anticipando la idea nietzscheana de que la creación de sí mismo podía llegar a tener el lugar que antes ocupaba la obediencia.

El éxito de las revoluciones antimonárquicas y anticlericales había inspirado a los románticos la idea de que el deseo de tener algo a lo que obedecer es un síntoma de falta de madurez. Estos éxitos habían hecho posible atisbar la construcción de una nueva Jerusalén sin la asistencia divina, creando, por tanto, una sociedad en la que los hombres y las mujeres llevaran las vidas perfeccionadas que, anteriormente, sólo habían parecido posibles en un paraíso past mortem, invisible e inmaterial. La imagen del progreso hacia una sociedad semejante - progreso horizontal, por así decirlo- comenzó a ocupar el lugar de las imágenes de ascenso vertical ofrecidas por Platón o Dante. La historia comenzó a reemplazar a Dios, a la Razón y a la Naturaleza como fuentes de esperanza humana. Cuando llegó Darwin, su relato de una historia prehumana animó esta sustitución. Pues se hizo posible vislumbrar una autocreación deliberada, una separación consciente del pasado como continuación del relato biológico de especies animales adelantándose unas a otras de modo perpetuo e inconsciente. 
Esta nueva explosión de autoconfianza humana es parte de un relato conocido, como lo es la sugerencia de que la animalización del hombre propuesta por Darwin no podia haber encontrado quien la creyese en tiempos anteriores. Muchos historiadores de las ideas han hecho notar que no habriamos sido capaces de aceptar que somos plenamente animales si todavía nos sintiéramos tan necesitados de la autoridad no humana como se sentían nuestros antepasados. Pero ahora quiero señalar algo menos conocido, a saber, que estos desarrollos hicieron igualmente posible aceptar que hay muchos modos diferentes de vida humana, todos igualmente válidos. Hicieron menos convincente la idea de una convergencia hacia la unidad. El ascenso vertical de los Muchos a lo Uno entraña dicha convergencia, pero el progreso horizontal puede ser pensado como una proliferación que está siempre incrementándose.

De Platón a Hegel, era natural pensar en los varios modos de llevar una vida humana como si estuvieran jerárquicamente ordenados. Los sacerdotes estaban por delante de los guerreros, los sabios por delante de lo vulgar, los patriarcas por encima de sus mujeres, los nobles sobre el pueblo llano, las Geisteswissenschaften por encima de las Naturwissenschaften. Dichas jerarquías se construían calculando la contribución relativa de la animalidad y del ingrediente extra añadido que nos hace verdaderamente humanos. Se decía que la proporción de ese ingrediente era menor en las mujeres que en los hombres, en los bárbaros menor que en los griegos, en los esclavos menor que en los hombres libres, en los verdaderos creyentes mayor que en los paganos, en los negros menor que en los blancos, etc. El modo común de justificar a la vez la subordinación y la conformidad era refiriéndose a dicho ingrediente y a dicha jerarquía. Desde que Platón escribiera el primera cuento de investigación vertical, ha sido natural plantear cuestiones tales como «iDónde queda esto en la gran cadena del ser?", o bien, "¿Qué nivel ocupa en la gran escalera del mundo, que lleva de la naturaleza hasta Dios?»

Sin embargo, después de Darwin, se hizo posible creer que la naturaleza no lleva a ninguna parte - que no tiene ningún fin premeditado. Esta idea, en cambio, sugería que la diferencia entre animales y humanos no es una prueba de la existencia de una deidad inmaterial. Sugería además que los humanos tienen que soñar cuál es el sentido de la vida humana, y no pueden apelar a un estándar no humano para determinar si su elección ha sido sabia. La última sugerencia hizo del radicalismo político algo intelectualmente viable. Fue posible pensar que el sentido de una vida humana podía tener muy poco que ver con el sentido de cualquier otra, sin que ello tuviera nada de malo. Esta última 
idea permitió a los pensadores disociar la necesidad de cooperación social (con la consiguiente necesidad de ponerse de acuerdo en lo que debe hacerse con fines públicos) de la pregunta griega: ¿qué es la Vida Buena para el Hombre?

Tales desarrollos permitieron considerar que el objetivo de la organización social era la libertad, más que la virtud, y considerar las virtudes más al modo de Menón que al de Sócrates: como una colección de tipos de excelencia sin relación entre ellas. Se hizo posible que el sentido rabelesiano del valor de una pura variedad humana sustituyera a la búsqueda platónica de unidad. En particular, estos desarrollos ayudaron a la gente a dejar de ver el sexo algo no más bestial ni "bajo" que cualquier otra fuente del placer humano (por ejemplo, la devoción religiosa, la reflexión filosófica o la creación artística). En el siglo XX, la idea de que somos ciudadanos libres de repúblicas gobernadas democráticamente ha acompañado la idea de que las fuentes particulares de placer que puedan tener nuestros vecinos no son asunto nuestro.

Esta última idea está en el corazón del Sobre la libertad de Mill, un tratado que comienza con un epigrafe (de Wilhelm von Humboldt) que afirma que el gran principio de la organización social es promover la mayor diversidad humana posible. Mill había aprendido de los Románticos que no puede tener sentido graduar los poemas o la gente según una escala única preestablecida; lo que cuenta es la originalidad y la autenticidad, más que la conformidad con un estándar precedente.

Así, a Mill y otros utilitaristas románticos les resultó posible pensar a la vez que la única respuesta plausible a la cuestión de "¿qué es intrínsecamente bueno?" es: "la felicidad humana», y admitir que esta respuesta no proporciona ninguna guía para elegir entre vidas humanas alternativas. Mill sabía que su vida y la de Harriet Taylor eran mejores que las de sus conciudadanos, igual que sabía que la vida de Sócrates era mejor que la de un cerdo. Pero estaba dispuesto a admitir que no podía probar esto de modo satisfactorio a sus conciudadanos, y concluyó que la ciudadanía democrática no requiere ningún acuerdo sobre el valor relativo de esos tipos de vida.

El momento culminante de este línea de pensamiento llegó con la renuncia del pragmatismo a la idea de que la verdad consista en la correspondencia con la realidad. Pues esta renuncia tiene como corolario que la búsqueda de la verdad no es distinta de la búsqueda de felicidad humana. Implica también que, para dar una visión unificada de cómo son las cosas, no hay ninguna necesidad de hacer que todas las proposiciones verdaderas sean coherentes. 
En 1912, un filósofo francés llamado René Berthelot tituló su libro: Utilitarismo romántico: estudio del movimiento pragmatista. El título era, creo, exactamente el correcto. También lo era la sugerencia de Berthelot de que Nietzsche y James estaban preocupados por las mismas cuestiones: dada una explicación Darwiniana de cómo hemos llegado hasta aquí, ¿podemos seguir pensando que el fin de nuestras investigaciones es dar Una Explicación Verdadera de Cómo Son realmente las Cosas? ¿`No deberíamos sustituir la idea de una pluralidad de objetivos diferentes de investigación —objetivos que requieren un ajuste mutuo pero que no requieren una síntesis-? ¿No podríamos pensar que las creencias verdaderas son gúas fiables para la acción humana, más que una representación precisa de algo no humano?

La afirmación utilitarista de que no tenemos otra meta que la felicidad humana, y que ningún mandamiento divino ni ningún principio filosófico tienen autoridad moral alguna si no contribuyen a lograr esa meta, tiene como corolario la afirmación pragmatista de que nuestro deseo de verdad no puede prevalecer sobre nuestro deseo de felicidad. En un sentido, lo críticos del utilitarismo y del pragmatismo tienen razón al decir que estas doctrinas convierten a los seres humanos en animales, pues ambas abandonan la idea de ese ingrediente extra anadido. Y la sustituyen por la idea de que los seres humanos, gracias a que han inventado un lenguaje, tienen un repertorio de conductas mucho mayor que el de las bestias, y, por ello, maneras de encontrar placer mucho más diversas e interesantes.

Usaré el término "pluralismo filosófico" para designar la doctrina de que hay una infinidad potencial de modos igualmente valiosos de llevar una vida humana, y que estos modos no pueden jerarquizarse por su grado de excelencia, sino sólo por su contribución a la felicidad de las personas que se conducen por ellos y de las comunidades a las que pertenecen esas personas. Esa forma de pluralismo está entretejida en los documentos fundadores del utilitarismo y del pragmatismo. William James, que se consideraba a si mismo un seguidor de las huellas de Mill - haciendo con nuestro concepto de verdad lo que Mill había hecho con nuestro concepto de acción correcta - dedicó la mitad de su vida filosófica a una cruzada contra la doctrina idealista de que el universo y la verdad tienen que ser, en algún sentido, algo Uno. En particular, insistía en que la ciencia y la religión podrían coexistir confortablemente tan pronto como se hiciera claro que ambas áreas de cultura servian a propósitos diferentes, y que esos propósitos diferentes requerian herramientas diferentes. La herramientas religiosas son necesarias para hacer posibles ciertos tipos de 
vida humana, pero no otros. Las herramientas cientificas no sirven de nada en muchos proyectos humanos, pero son muy útiles en otros.

Nietzsche, a quien Berthelot describía como un "pragmatista alemán", estaba de acuerdo con James en lo que se refiere a la verdad. Invirtio una gran parte de su tiempo en luchar contra la idea de que lo que llamamos "conocimiento" es algo más que un conjunto de trucos para mantener viva y sana una especie. Mostrando tanta ignorancia como ingratitud, Nietzsche se burlaba de Mill y Darwin, pero no dudó en apropiarse de sus mejores ideas. Si hubiera vivido lo bastante como para leer a James, es probable que no hubiera reconocido al discípulo de Emerson, pero se habría burlado de él, llamándole mercader yanqui, calculador y plebeyo. Y, sin embargo, Nietzsche se habría hecho eco de las apelaciones de James y Dewey por un futuro que produjese una profusión en expansión constante de nuevos tipos de vida humana, nuevas clases de ser humano.

Creo que, para entender la vida intelectual postdarwinina, es importante captar la importancia del rechazo de los pragmatistas a aceptar la concepción de la verdad como correspondencia, o sea la teoría de que las verdaderas creencias son representaciones precisas de una realidad preexistente. Ello acompaña a su negativa a creer que la realidad no humana tenga un carácter intrínseco, un carácter que tengan que respetar los seres humanos. Nietzsche y James sustituyeron nociones como la de "Realidad" o «Naturaleza» por la noción biologista de entorno. El entorno en el que viven los seres humanos nos plantea problemas, pero, a diferencia de una Razón o una Naturaleza capitalizada, no le debemos respeto ni obediencia. Nuestra tarea es dominarlo, adaptarnos a él, más que representarlo o corresponderle. La idea que de que tenemos un deber moral de corresponder a la realidad es, para Nietzsche y James, tan idiotizante como la idea de que todo el deber del hombre consiste en agradar a Dios.

El vínculo entre darwinismo y pragmatismo es clarísimo cuando uno se hace la siguiente pregunta: ¿En qué punto dejaron los organismos biológicos de enfrentarse a la realidad para empezar a representársela? Plantear el acertijo es sugerir la respuesta: puede que nunca empezaran a representársela. Puede que toda la idea de representación mental fuera sólo una metáfora estéril, sin valor efectivo. Puede que esta metáfora estuviera inspirada por la misma necesidad de entrar en contacto con una poderosa autoridad no humana que hizo a los curas creerse más verdaderamente humanos que los guerreros. Puede que, una vez que las revoluciones francesa e industrial les habían dado a los seres 
humanos una nueva confianza en sí mismos, pudieron abandonar la idea de representar la realidad y sustituirla por la idea de usarla.

Abandonar la teoría de la verdad como correspondencia significa dejar de insistir en que la verdad, como la realidad, es una y continua. Si una creencia verdadera es simplemente el tipo de creencia que sobrepasa la competición como regla de para una acción futura con exito, puede que no haya necesidad de reconciliar todas las creencias de una persona con todas las creencias de otra ninguna necesidad de intentar ver la realidad como algo firme y constante en su totalidad. Quizá, como es sabido que decía James, es posible compartimentalizar nuestras creencias, de modo que no haya necesidad, por ejemplo, de reconciliar la asistencia de uno a misa con su trabajo como biólogo evolucionista. El conflicto entre creencias adoptadas para fines diversos sólo puede surgir cuando nos comprometemos en proyectos de cooperación social, cuando necesitamos ponernos de acuerdo sobre lo que hay que hacer. Así, el propósito de una utopía política se desliga de la religión y de la ciencia. No tiene fundamentos religiosos, filosóficos o científicos, sino sólo utilitaristas o pragmáticos. Desde el punto de vista pragmático, una utopía liberal democrática no es más verdadera para la naturaleza humana o las demandas de una ley moral antihistórica que una tiranía fascista. Pero es mucho más probable que produzca una felicidad humana mayor. Una sociedad perfecionada no vivirá según un patrón preexistente, sino que será un logro artístico, alcanzado por el mismo largo y difícil proceso de ensayo y error que se requiere para cualquier otro esfuerzo creativo.

Hasta aquí, he intentado mostrar que el darwinismo, el utilitarismo y el pragmatismo conspiraron para exaltar la pluralidad sobre la unidad -cómo la disolución de la tradicional imagen teológico-metafisica del mundo ayudó a los intelectuales europeos a abandonar de la idea de la Única Explicación Verdadera de Cómo Son las Cosas. Las nuevas esperanzas sociales que llenaron todo el siglo XIX les ayudaron a cumplir esta transvaloración de todos los valores filosóficos tradicionales, y el pluralismo filosófico resultante reforzó la sensación de que una sociedad perfeccionada haría posible una diversidad humana en constante y continua proliferación. Al final de ese siglo, parecía completamente plausible que la raza humana, que había roto barreras que venian de la Antigüedad, estaba a punto de crear una comunidad global, cosmopolita, socialdemócrata y pluralista. Las instituciones de esta sociedad perfeccionada no sólo eliminarían las desigualdades tradicionales, sino que dejarían a sus miembros espacio suficiente para perseguir sus visiones individuales de la perfección humana. 
Trataré ahora algunas cuestiones que, durante las últimas décadas, han empezado a convertirse en un lastre para los intelectuales, y que se suelen denominar "los problemas de la postmodernidad". Son cuestiones planteadas por el hecho de que, como dice Clifford Geertz, el liberalismo, la aspiración a semejante sociedad perfeccionada, es uél mismo un fenómeno culturalmente específico, nacido y perfeccionado en Occidente». El propio universalismo con el que está comprometido el liberalismo , y que él promueve, continua Geertz,

"lo ha llevado a un conflicto abierto con otros universalismos de intenciones similares, muy sef́aladamente con el iniciado por un Islam renaciente, y con una gran cantidad de versiones alternativas del bien, de lo correcto y de lo indudable, la japonesa, la hindú, la africana, la singapurense, a las que el liberalismo les parece sólo un intento más de imponer valores occidentales al resto del mundo: la continuación del colonialismo por otros mediosn ${ }^{3}$.

Lo que Geertz dice del liberalismo también es verdadero de sus socios filosóficos, el utilitarismo y el pragmatismo. La mayoría de quienes se sienten atraidos por estas dos doctrinas filosóficas son gente que ha decidido previamente que su utopía favorita es la utopía liberal tal como la describe Mill en Sobre la libertad: un mundo en el que no hay nada sagrado, salvo la libertad de llevar cada uno la vida que le parece, y no está prohibido nada que no interfiera con la libertad de los otros. Si pierdes la fe en esta utopía, puedes empezar a dudar del pluralismo filosófico.

Aunque esta relación de carácter social es real e importante, debería estar claro que ni el utilitarismo ni el pragmatismo entrañan un compromiso con el liberalismo. Por esta razon, Nietzsche puede ser tan buen pragmatista como James, y el Gran Inquisidor de Dostoyevski puede ser tan buen utilitarista como Mill. Por otro lado, el liberalismo está muy cerca de entrañarlos a ellos. Pues, aunque los utilitaristas románticos no quieren necesariamente desencantar el mundo, sí que quieren, ciertamente, desencantar el pasado. De modo que necesitan evaporar muchas cosas que antes parecían muy sólidas. Las redefiniciones de lo "correcto" y lo "verdadero" que respectivamente ofrecen Mill y James son indispensables en ese proceso de fusión. Pues cualquier definición

3 GeERTZ, cap. lii, pág. 21. 
no utilitaria de lo "correcto" y cualquier definición no pragmatista de lo "verdadero" prestarán ayuda y confort a la idea de que hay una autoridad -por ejemplo, la ley moral eterna, o la estructura intrínseca de la realidad- que prevalece sobre el acuerdo entre seres humanos libres acerca de lo que hay que hacer o creer.

Geertz dice que los partidarios del liberalismo

"tienen que reconcebirlo como una visión, no desde ningún sitio, sino desde algún lugar concreto de (una cierta especie de) experiencia política occidental, una declaración... sobre lo que nosotros, que somos los herederos de esa experiencia, pensamos que hemos aprendido sobre cómo gentes diferentes pueden vivir juntas entre ellas con cierto grado de concordia" 4 .

Éste es exactamente el modo en que Dewey quería que concibiesemos el pragmatismo: no como el resultado de una comprensión más profunda de la naturaleza de la verdad o del conocimiento, sino como la visión de la verdad y el conocimiento que uno probablemente adoptará si, como resultado de su propia experiencia con varias alternativas sociopolíticas, llegara a considerar como esperanza suprema la creación de la utopla liberal bosquejada por Mill. Los pragmatistas se sienten como en casa con la idea de que la teoría política debería verse a sí misma como unas sugerencias para la acción futura que surgen de la experiencia histórica reciente, más que como el intento de legitimar el resultado de esta experiencia refiriéndose a algo ahistórico.

Pero los escépticos que Geertz cita, la gente que sospecha que el liberalismo es un intento de imponer el resultado de una experiencia específicamente europea a pueblos que no han tenido arte ni parte en esa experiencia, sugerirán quizá que la confianza europea en el liberalismo y sus corolarios filosóficos es simplemente la confianza en el exito que ha tenido Europa en someter a su voluntad al resto del mundo. ¿Cómo podéis decir los europeos, preguntarían esos escépticos, si vuestra devoción por el liberalismo es el resultado de sus méritos intrínsecos o es simplemente un resultado del éxito de las sociedades liberales en hacerse con el control de la mayoría de los recursos y de la mayoría de la población del mundo?

4 GeErTZ, cap. lii, pág. 23. 
Quizá, sugiere el escéptico, la antigua fe ilimitada en el liberalismo y sus corolarios filosóficos era resultado de una convicción tácita del triunfo del liberalismo. Desde el comienzo del período colonialista hasta el pasado reciente le parecía obvio a la mayoría de los europeos, y plausible a la mayoría de los no europeos, que nada podría resistir la fuerza del ejemplo intelectual europeo, igual que nada había podido resistir la fuerza del poder comercial y militar de Europa. Pero quizá, la transvaloración de los valores filosóficos tradicionales a la que me he referido —el desplazamiento de la unidad a la pluralidad—, ¿no era simplemente un intento de los filósofos por subirse al tren económico y militar? Quizá la filosofía no hacía otra cosa que seguir las banderas.

La respuesta que Dewey daría a este escéptico postcolonial sería más o menos como sigue: desde luego, puede que el utilitarismo y el pragmatismo nunca hubieran levantado el vuelo sin el impulso del triunfalismo colonialista e imperialista Pero, ¿y qué? La cuestión no es si la popularidad de estas visiones filosóficas era producto de esta o aquella posesión transitoria del poder, sino si alguien tiene mejores ideas o mejores utopías. Nosotros, los pragmatistas, no argumentamos que la Europa moderna tenga una visión superior de las realidades eternas y ahistóricas. No reclamamos una racionalidad superior. Sólo reivindicamos un éxito experimental: hemos alcanzado un modo de dar a la gente algún grado de concordia, de incrementar la felicidad humana, que parece más prometedor que cualquier otra de las vías que se han propuesto hasta ahora.

A fin de evaluar esta respuesta, consideremos algunas de las razones por las que Europa ya no parece ser la vanguardia de la raza humana, razones por las que parece absurdamente improbable que vayamos a tener nunca una utopía liberal global. He aquí tres:

1. No es posible tener un gobierno democrático europeo sin algo parecido a un nivel de vida europeo — sin la clase media, sin las instituciones de sociedad civil bien establecidas que hacen posible un estándar semejante. Sin ellas, no se puede tener un electorado suficientemente educado y que disponga de tiempo libre para tomar parte en el proceso democrático. Pero hay demasiada gente en el mundo, y demasiado pocos recursos naturales para que ese nivel de vida sea accesible a todos los seres humanos.

2. Los codiciosos y egoístas cleptócratas se han vuelto mucho más sofisticados en décadas recientes. Los generales chinos y nigerianos, y sus colegas en todo el mundo, han aprendido de los fracasos del totalitarismo del siglo XX que es mejor evitar la ideología y ser pragmáticos. Mienten, estafan y roban de 
modo mucho más disimulado y sofisticado que, por ejemplo, las antiguas nomenclaturas comunistas. Así, el final de la guerra fría no permite ningún optimismo en cuanto al progreso de la democracia, por mucho que ésta haya hecho a favor del triunfo del capitalismo.

3. Conseguir una utopía liberal a escala global requeriria establecer una federación mundial que ejerciera un monopolio global de la fuerza - la clase de federación que se puede encontrar descrita en cualquier utopía de ciencia ficción que tenga lugar en el siglo XXI. (Como ha señalado Michael Lind, las únicas historias de ciencia ficción que postulan la permanencia de una pluralidad de Estados-nación soberanos son distopías apocalípticas.) Pero la probabilidad de que una federación semejante llegue a tener lugar es mucho más pequeña de lo que lo era cuando se fundó la ONU en 1945. La continua fragmentación de viejos Estados-nación, antiguas colonias y federaciones, hace menos posible un gobierno mundial cada año que pasa. Asl, incluso si la tecnología pudiera permitirnos equilibrar de algún modo la población y los recursos, e incluso si pudiéramos liberar a los pobres de los cleptócratas, seguiríamos siendo igual de desgraciados. Pues, tarde o temprano, unos idiotas de uniforme empezarán a apretar botones nucleares y nuestros nietos vivirán en una distopía como la mostrada en la película Mad Max (Road Warrior).

Creo que estas son tres posibles razones para creer que ni la libertad democrática ni el pluralismo filosófico sobrevivirán al próximo siglo. Si yo fuera un dios del Olimpo jugando a las quinielas, apostaría muy gustosamente con mis olímpicos compañeros divinos que el pragmatismo, el utilitarismo y el liberalismo sólo serán un débil recuerdo entre los mortales dentro de cien años. Pues puede que, para entonces, existirán muy pocas librerlas sin expurgar, y muy poca gente habrá of́do hablar de Mill, Nietzsche, James o Dewey, ni de sindicatos libres, prensa libre o elecciones democráticas.

Sin embargo, ninguna de estas tres razones de por qué los sueños de los europeos del siglo XIX pueden ser irrelevantes para el siglo XXI sugiere ninguna razón para sospechar de la superioridad del liberalismo, el pragmatismo o el utilitarismo frente a sus diversos rivales, igual que el colapso del Imperio Romano recientemente convertido no le dio a Agustín y sus contemporáneos ninguna razón para dudar de la superioridad del Cristianismo respecto al paganismo. Ni tampoco el contemplar tales razones nos ayuda mucho a hacer lo que Geertz nos pide que hagamos cuando reclama la creación de «un nuevo tipo de política», una política 
"que no considere la reivindicación étnica, religiosa, racial, linguística o regional como irracionalidad arcaica e ingenerada que debe ser suprimida y transcendida, una locura desacreditada o una oscuridad ignorada, sino que, como como con cualquier otro problema social - la desigualdad, digamos, o el abuso de poder- la vea como una realidad a la que hay que enfrentarse, tratar con ella de algún modo, modularla, llegar arreglárselas con ella» ${ }^{5}$.

La primera vez que leí esta frase en el libro de Geertz, me pareció que estaba de acuerdo. Pero al volverlo a pensar, me di cuenta de que estaba más de acuerdo con el espíritu que con la letra. El espíritu, creo, es que deberíamos tratar con la gente que exhibe esa reivindicación como deberíamos tratar con todos los demás conciudadanos de una federación mundial: que deberíamos tomar en serio sus problemas y hablar a fondo de ellos. Pero si uno acepta literalmente la sentencia de Geertz, puede objetar razonablemente que no hay contradicción entre considerar algo una irracionalidad ingenerada y arcaica y considerarla como una realidad a la que hay que enfrentarse, con la que tratar de algún modo, modularla, arreglárselas con ella.

Creo que es importante insistir en esta ausencia de contradicción, porque se suele decir que los pluralistas filosóficos como yo tienen que abjurar de la noción de «irracionalidad". Pero no es así. Podemos perfectamente seguir usando la noción mientras lo hagamos para designar la disposición a ignorar los resultados de la experiencia pasada, en lugar de significar una despedida de las órdenes de una autoridad ahistórica llamada Razón.

En el curso de los últimos dos siglos, hemos aprendido un montón de cosas sobre cómo las razas y las religiones pueden vivir en armonía mutua. Si olvidamos estas lecciones, es razonable que se nos llame irracionales. Tiene un buen sentido pragmático y pluralista decir que las naciones del mundo son irracionales al no crear un gobierno mundial al que rendir su soberanía y sus cabezas nucleares, que los alemanes eran irracionales al aceptar las propuestas de Hitler para que expropiasen a sus vecinos judíos, y que los campesinos serbios eran irracionales al aceptar la sugerencia de Milosevic de que saqueasen y violasen a vecinos con los que habían estado viviendo en paz durante cincuenta años.

5 GEERTZ, cap. lii, pág. 27. 
En la medida en que el pensamiento filosófico "postmoderno" se identifica con un relativismo cultural descerebrado y estúpido - con la idea de que cualquier imbecilidad que se autodenomine cultura es digna de respeto-, ese pensamiento no me sirve de nada. Pero no veo por qué lo que he llamado "pluralismo filosófico tiene que entranar semejante estupidez. La razón para intentar la persuasión en lugar de la fuerza, para hacer todo lo que podamos a fin de llegar a un acuerdo con gente cuyas convicciones sean arcaicas o ingeneradas*, es, simplemente, que el uso de la fuerza, de la burla o del insulto tiene muchas probabilidades de disminuir la felicidad humana.

No hace falta que añadamos a este sabio consejo utilitarista, como suplemento, la idea de que toda cultura tiene algún valor intrínseco. Hemos aprendido la futilidad de intentar asignar a todas las culturas y personas su lugar dentro de una escala jerárquica, pero darse cuenta de ello no impugna el hecho obvio de que hay montones de culturas de las que preferiramos prescindir, igual que hay montones de personas de las que prefeririamos prescindir. Decir que no hay tal escala, que simplemente somos unos animales inteligentes que intentan incrementar su felicidad reinventándose continuamente a sí mismos, no tiene consecuencias relativistas. La diferencia entre el pluralismo y el relativismo cultural es la diferencia entre la tolerancia justificada pragmáticamente y la irresponsabilidad descerebrada.

Todo esto por lo que se refiere a mi sugerencia de que el insignificante término "postmodernismo" es el resultado de la incapacidad para resistir las exigencias del pluralismo filosófico, combinado con un temor más que razonable a que la historia esté a punto de dar un giro en contra nuestra. Sin embargo, quiero concluir, algo bruscamente, con unas palabras finales sobre la impopularidad del término, sobre la retórica de quienes usan esta palabra como un término del que abusar.

Muchos de mis colegas filósofos usan el término «relativismo postmodernista" como si fuera un pleonasmo, como si los utilitaristas, los pragmatistas y los pluralistas filosóficos en general hubieran cometido una especie de "traición de los secretarios», como la llamaba Julien Blenda. Sugieren a menudo que si los filósofos hubieran permanecido unidos detrás de las buenas y antiguas verdades teológico-metafísicas -o que si a James y a Nietzsche los hubieran estrangulado en la cuna- el destino de la humanidad hubiera sido diferente. Del mismo modo que los fundamentalistas cristianos nos dicen que la tolerancia de la homosexualidad conduce al colapso de la civilización, aquellos 
a quienes les gustaría mandarnos de vuelta a Platón y Kant creen que el utilitarismo y el pragmatismo pueden debilitar nuestra fibra moral e intelectual. El triunfo de los ideales democráticos europeos, sugieren, habría sido mucho más probable si los pluralistas filosóficos hubieran tenido la boca cerrada.

Pero razones para pensar que esos ideales no van a triunfar, como las tres que he enunciado más arriba, no tienen nada que ver con cambios de imagen filosóficos. Ni la ratio de población y recursos, ni el poder que la moderna tecnología pone en manos de los cleptócratas, ni la intransigencia provinciana de los gobiernos nacionales, tienen nada que ver con tales cambios. Sólo la creencia arcaica e injustificada en que un poder no humano que se sienta ofendido vaya a castigar a quienes no lo adoran hace posible ver una conexión entre el desplazamiento intelectual de la unidad a la pluralidad y esas diversas razones concretas para el pesimismo histórico. Este desplazamiento no nos deja nada con lo que impulsar nuestras esperanzas sociales, pero ello no significa que estas esperanzas tengan algo equivocado. La esperanza social utópica que surgió en la Europa del siglo XIX sigue siendo la más noble creación imaginativa de que tenemos recuerdo. 